Supplement of Biogeosciences, 17, 3797-3814, 2020 https://doi.org/10.5194/bg-17-3797-2020-supplement (C) Author(s) 2020. This work is distributed under the Creative Commons Attribution 4.0 License.

(c) (1)

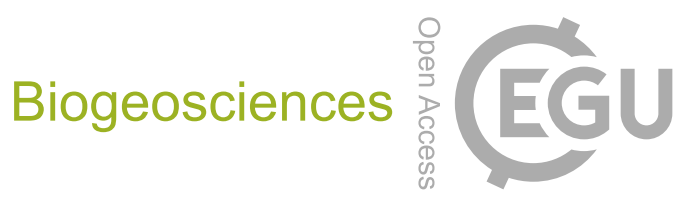

Supplement of

\title{
Organic carbon characteristics in ice-rich permafrost in alas and Yedoma deposits, central Yakutia, Siberia
}

Torben Windirsch et al.

Correspondence to: Torben Windirsch (torben.windirsch@awi.de)

The copyright of individual parts of the supplement might differ from the CC BY 4.0 License. 


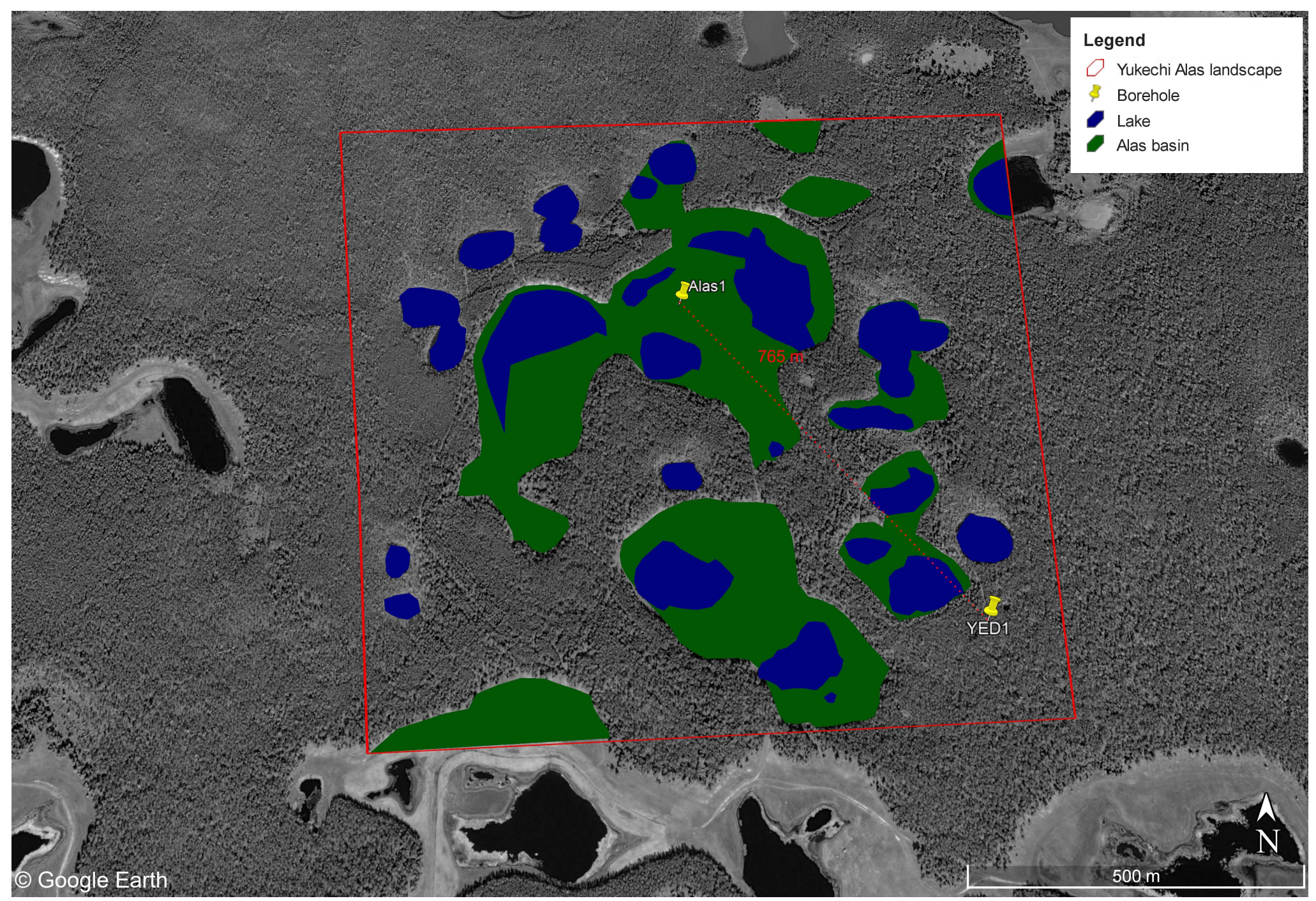

Figure S1 - Digital mapping of the Yukechi Alas landscape (red); lakes were digitalized in blue, Alas basins were digitalized in green; sampling locations Alas1 and YED1 marked in yellow; the $765 \mathrm{~m}$ distance between YED1 and Alas1 is marked by a red dotted line; satellite image: (c) Google Earth. 


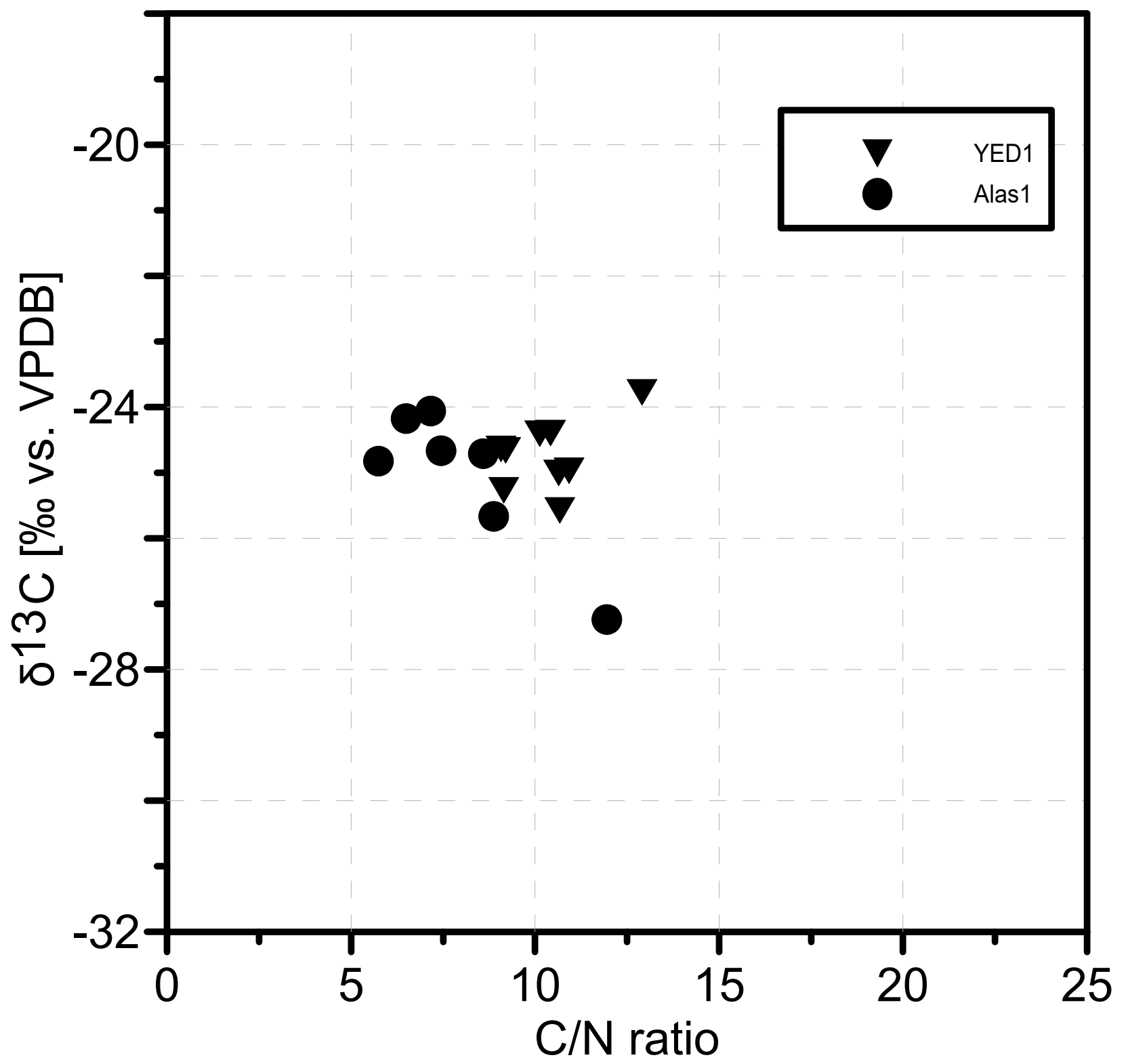

Figure S3 - C/N values of YED1 (triangles) and Alas1 (dots) plotted over $\delta^{13} \mathrm{C}$ values. 


\section{Clay}

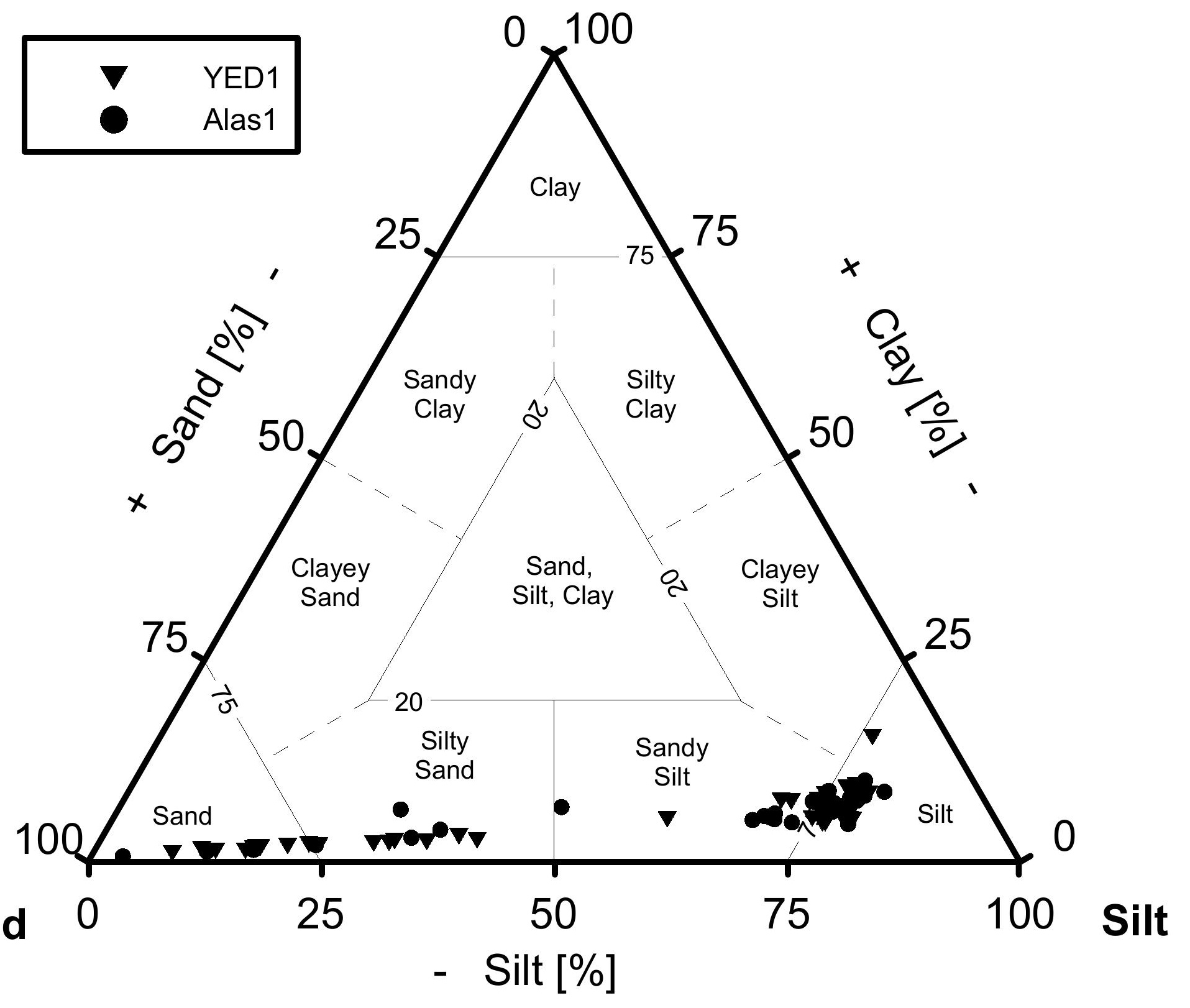

Figure S4 - Sediment triangle after Shepard showing the grain size composition. 


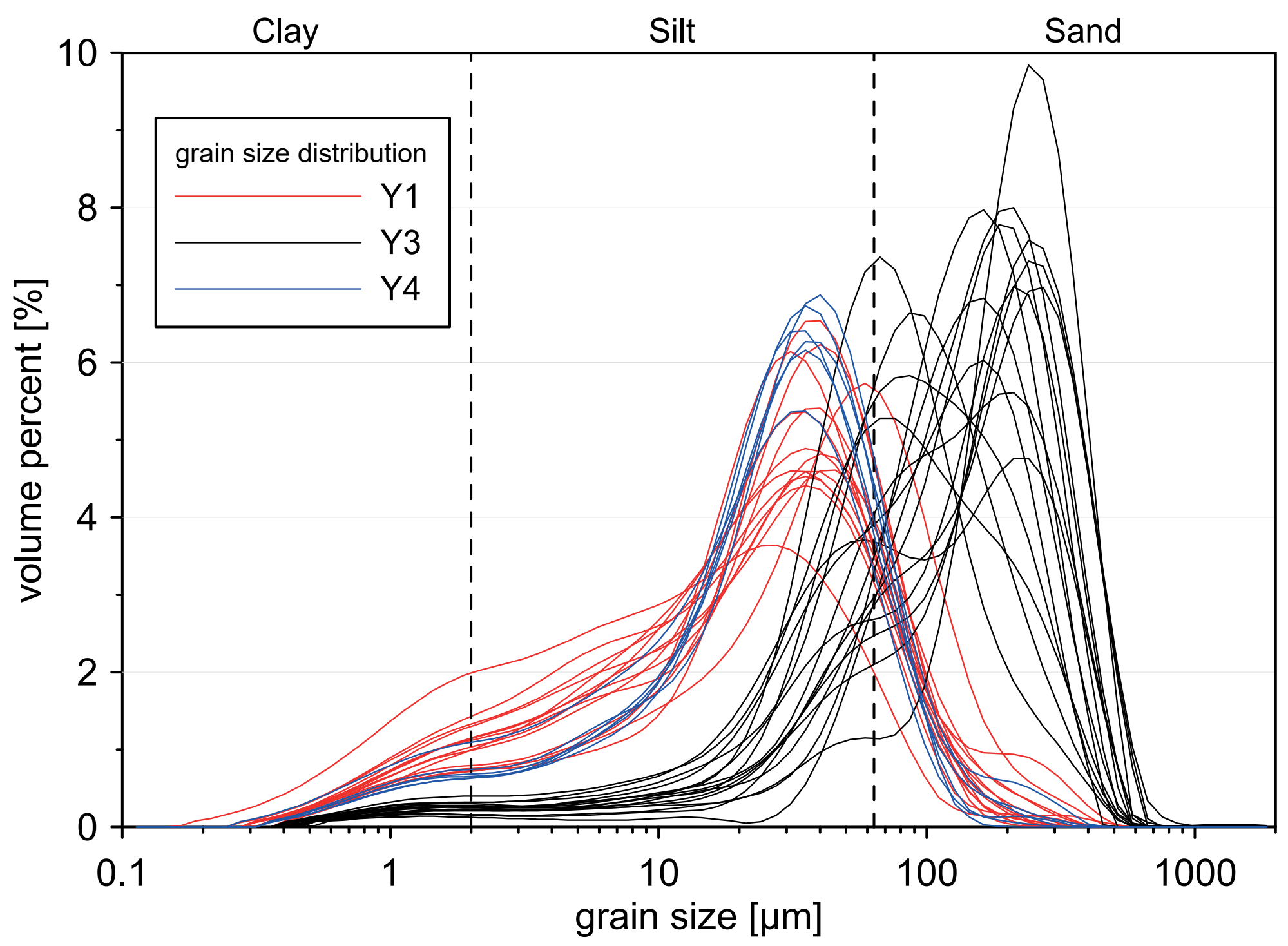

Figure S5 - Grain size distribution for the YED1 core; Y1 to Y4 indicate the different stratigraphical units; core unit $Y 2$ did not hold enough sediment. 


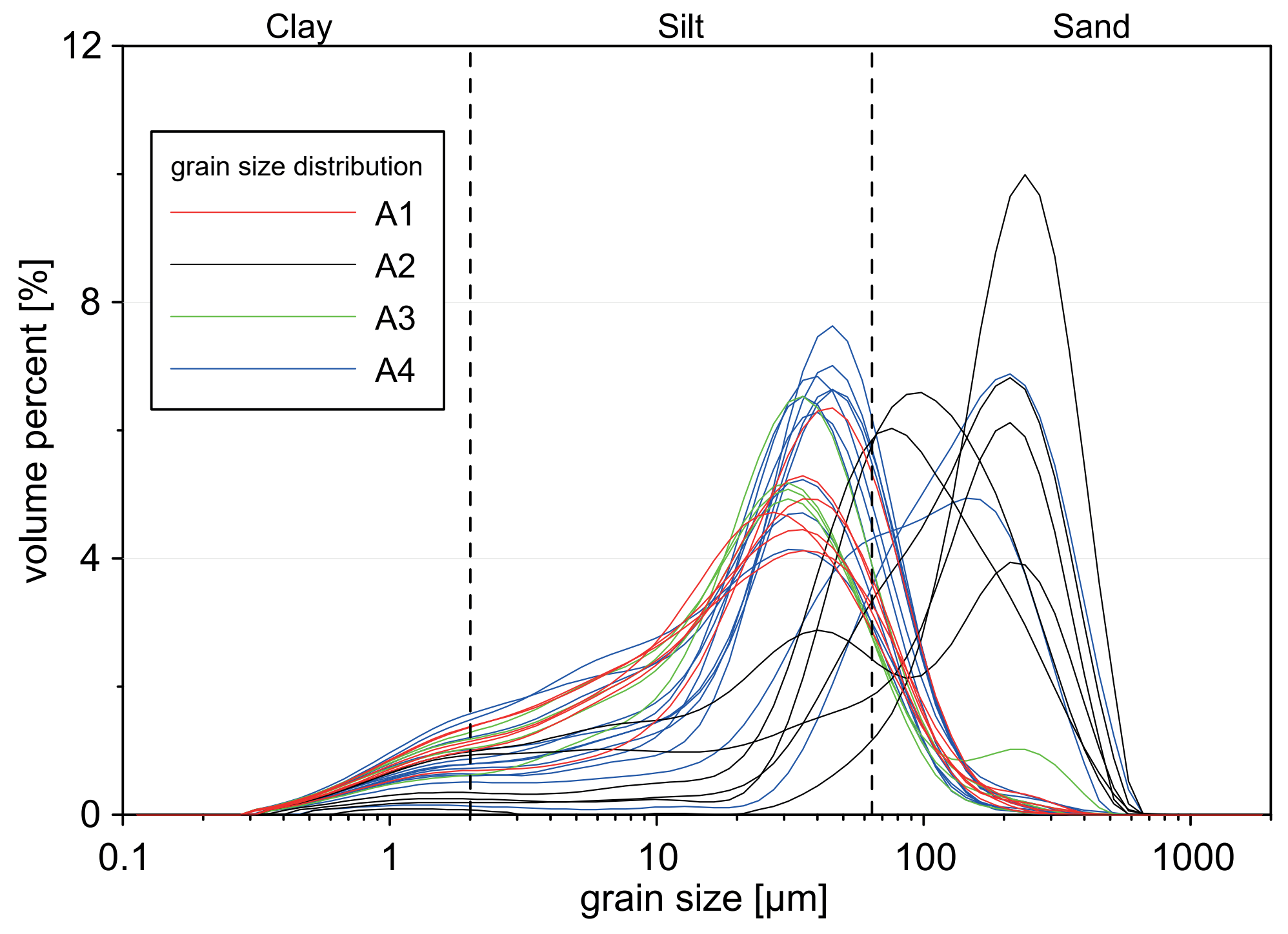

Figure S6 - Grain size distribution for the Alas1 core; A1 to A4 mark the different stratigraphic units. 


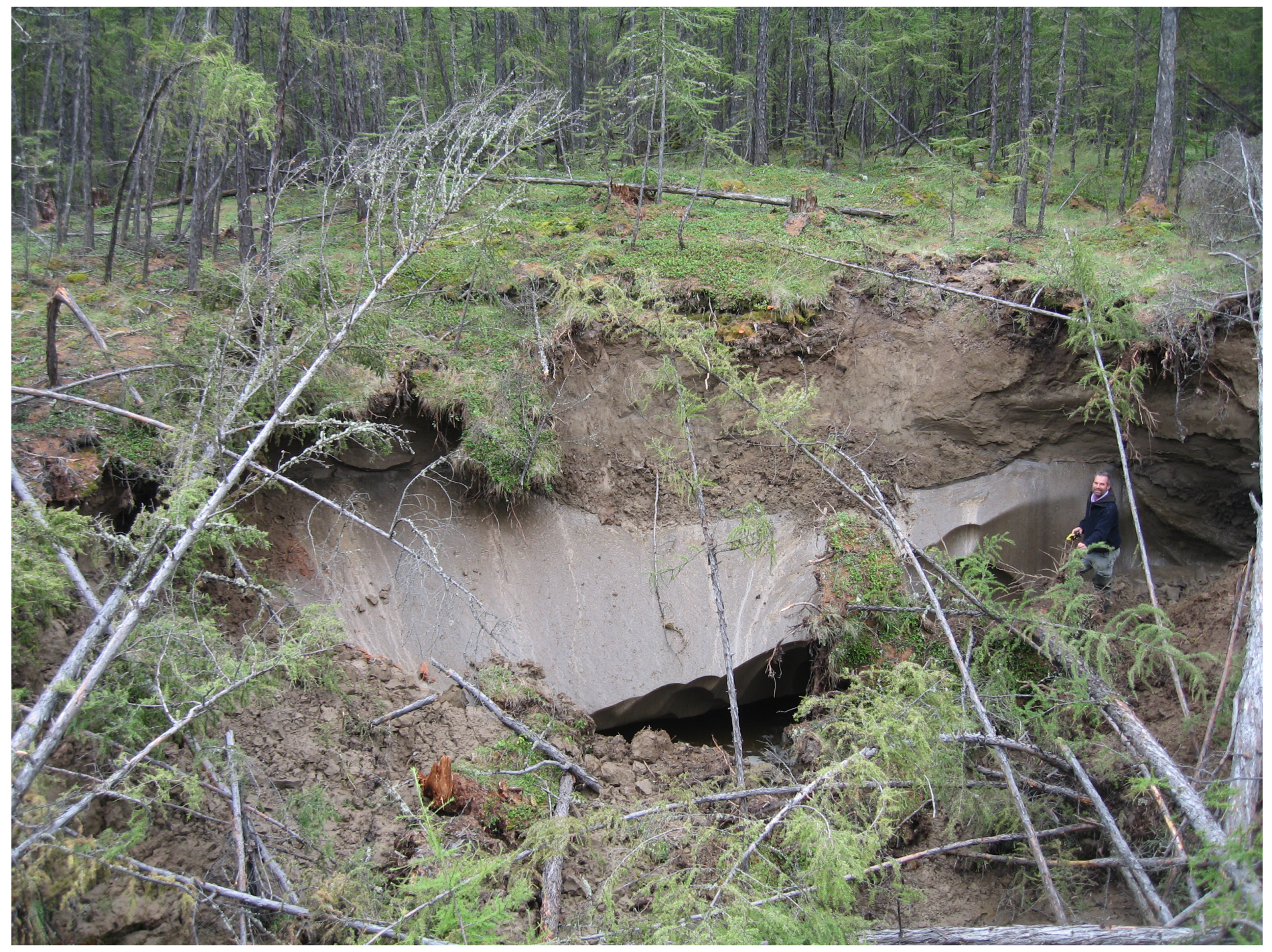

Figure S7 - Photo of a large ice wedge found on the Abalakh Terrace, Central Yakutia, approximately $30 \mathrm{~km}$ east of the Yukechi Alas landscape; photo by Mathias Ulrich. 